\title{
MULTI-TEMPORAL HIGH-RESOLUTION LANDSLIDE MONITORING BASED ON UAS PHOTOGRAMMETRY AND UAS LIDAR GEOINFORMATION
}

\author{
C.-L. J. Hung ${ }^{1}$, C.-W. Tseng1, ${ }^{1,}$, M.-J. Huang², C.-M. Tseng ${ }^{3}$, K.-J. Chang², * \\ 1 Division of Watershed Management, Taiwan Forestry Research Institute, Taipei, Taiwan - (hungc, a1211)@tfri.gov.tw \\ ${ }^{2}$ Dept. of Civil Engineering, National Taipei University of Technology, Taipei, Taiwan - Megan31200@gmail.com; \\ epidote@ntut.edu.tw \\ ${ }^{3}$ Dept. of Land Management and Development, Chang Jung Christian University, Tainan, Taiwan - cmtseng@mail.cjcu.edu.tw
}

\section{Commission VI, WG VI/4}

KEY WORDS: UAS/UAV, DEM of Difference (DoD), geomorphometry, environment change detection, accuracy assessment

\begin{abstract}
:
Due to the high seismicity and high annual rainfall, numerous landslides occurred and caused severe impacts in Taiwan. Typhoon Morakot in 2009 brought extreme and long-time rainfall, and caused severe disasters. After 2009, numerous large scale deep-seated landslides may still creeping, however not necessary easily to inspect the activity. In recent years, the remote sensing technology improves rapidly, providing a wide range of image, essential and precious geoinformation. Accordingly, the Small unmanned aircraft system (sUAS) has been widely used in landslide monitoring and geomorphic change detection. This study used UAS to continuously monitor a landslide area in Baolai Village in southern Taiwan, which had a catastrophic landslide event triggered by heavy rainfall caused by Typhoon Morakot in 2009. In order to accesses the potential hazards, this study integrates UAS, field geomatic survey, terrestrial laser scanner (ground LiDAR), and UAS LiDAR for sequential data acquisition since 2015. Based on the methods we are able to construct multi-temporal and high resolution DTMs, so as to access the activity and to monitoring the creeping landslides. The data set are qualified from 21 ground control points (GCPs) and 11 check points (CPs) based on real-time kinematic-global positioning system (RTK-GPS) and VBS RTK-GPS (e-GNSS). More than 10 UAS flight missions for the study areas dated since 2015, for an area large than 5-40 $\mathrm{Km}^{2}$ with 8-12 $\mathrm{cm}$ spatial resolution (GSD). Then, the datasets was compared with the airborne LiDAR data, to evaluate the quality and the interpretability of the dataset. Since early 2018, we integrate UAS LiDAR technology to scanning the sliding area. The density of the point cloud data sets are higher than 250 and 100 points $/ \mathrm{m}^{2}$ for the total and ground point, respectively. The spatial distributions of geomorphologic changes were quantified firstly with the GCPS and CPs. The potential disaster was evaluated at different times, and the result reveals that most active regions were on the eastern side of the landslide. Significant changes in elevation were detected before the middle of 2017, however reactivated again since middle of 2018. The results of this study provide not only geoinfomatic datasets of hazardous area, but also for essential geomorphologic information/methods for other study, and for hazard mitigation and planning, as well.
\end{abstract}




\section{TINTRODUCTION}

The use of digital elevation models (DEM) for geomorphological monitoring is critical for assessing landslide hazard potential after landslides have occurred. Unfortunately, large-scale, high-spatial-resolution observations of catastrophic landslide areas are inaccessible for direct field measurements and dangerous. High-resolution DEMs of the Earth's surface can be generated through Airborne LiDAR that can produce bareearth point-cloud data with 1-m LiDAR pixels (Chen et al., 2005; Chang et al., 2005, 2006, 2010; Chan et al., 2007; Hsieh et al., 2016; Chang et al., 2018; Hung et al., 2018). However, high resolution geoinformatic is not easy to assess. In recent years, large-scale, high-spatial-resolution land surface mapping benefits from applications of small unmanned aircraft system (UAS) with multiple view stereo (MVS) and structure-frommotion (SfM) photogrammetry for studies may aspects, especially for landslide investigation and monitoring.

Taiwan, due to the high seismicity and high annual rainfall, numerous landslides triggered every year and severe impacts affect the island. In recent years, the remote sensing technology improves rapidly, providing a wide range of image, essential and precious information. In order to evaluate potential hazards, the high precision terrain geomorphology in different periods is essential, so as to monitoring and assessment the hazards. For these purpose, we try to integrate several UAV based technologies, especially by unmanned aircraft system optical light detection and ranging (UAS LiDAR).

\section{STUDY AREA}

The study area is situated in Baolai Village in southern Taiwan (Fig.1). The composed rocks are mainly of shaley slate interbedded with thin metasandstone, and situated right close to main boundary fault- The Laonong Fault. Highly deformed fractured rocks dominate the rock strength in this area. Typhoon Morakot on August 8, 2009, brought more than 3000mm with maximum rainfall $>100 \mathrm{~mm} / \mathrm{hr}$, struck study area and caused severe landslides in Laonong Stream watershed. Baolai village is one of the most populous village. Since 2009, landslides active continuously, however not sufficient attention has attract since then.

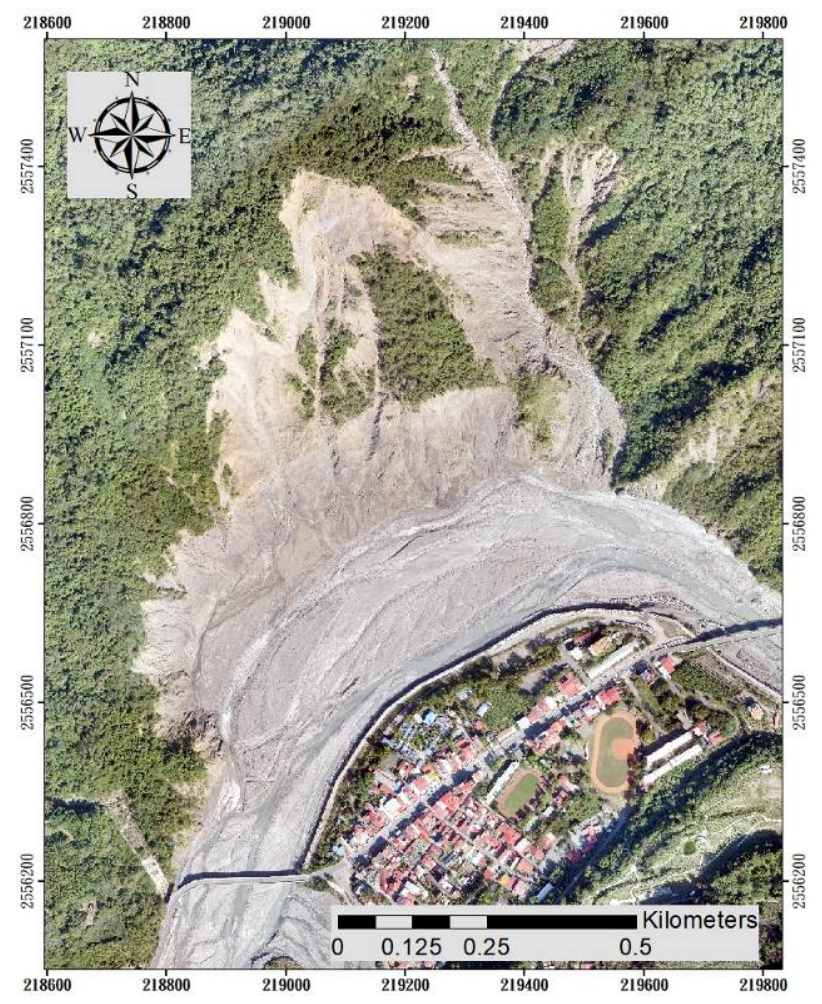

Figure 1. Study area

\section{METHODS}

A UAV, commonly known as a drone, is an aircraft without human pilot on board. UAV based remote sensing applications have been reported by researchers in various disciplines, especially in morphotectonic study, e.g. Deffontaines et al. (2017, 2018, 2019), Chang et al. (2018), etc. In order to monitoring the landslides, high-resolution images are acquired since 2015. The home-made UAVs mounted with Sony ILCEQX1 camera and 16mm SEL16F2.8 lens was used in this study. The open source Ardupilot Mega 2.6 autopilot (APM) autopilot system, XBee radio telemetry, and Mission Planner are integrated. The flight missions were planned with about 300$500 \mathrm{~m}$ above ground level, covered an area of about 5-40 km² with about 8-12 cm ground sampling distance (GSD) in one single flight mission. The mission are orgainzed by $>85 \%$ endlap and $50 \%$ sidelap repeated adjacent photographs to ensure full coverage and quality of geoinformatic datasets. The UAS was launched by hand; it flew, turns on the camera, captured photos, turns off the camera, and then glided back to the ground, the entire fly mission process autonomously. The whole process was conducted using a preprogrammed flight mission organized by a ground control system, and remote controlled either by the ground control station (GCS) and/or by the transmitter.

More than 10 UAS flight missions for the study areas dated since 2015. Fig.2 demonstrates the mosaic true-orthorectified images gathered by UAS, denoted with date of acquisition. Then, the datasets was compared with the airborne LiDAR data, to evaluate the quality and the interpretability of the dataset. Since early 2018, we integrate UAS LiDAR technology to scanning the sliding area. The density of the point cloud data sets are higher than 250 and 100 points $/ \mathrm{m}^{2}$ for the total and ground point, respectively. The spatial distributions of geomorphologic changes were quantified firstly with the GCPS and CPs. 


\section{RESULTS}

In order to access the landslide activity, different methods have been involved, including orthomosaic image to identified landslide regions, DSM to evaluated geomorphologic change and volume calculation, image correlation to calculate horizontal displacement by means of Particle image velocimetry (PIV) (Chang et al., 2005) and image matching.

\subsection{Field Survey}

In order to constraint and to evaluate the quality of the dataset generate in this study, 21 ground control points (GCPs) and 11 check points (CPs) based on real-time kinematic-global positioning system (RTK-GPS) and VBS RTK-GPS (e-GNSS) taken in different periods. Field geomatic results shows the precision of the GCPs and CPs are $0.015 \mathrm{~m}, 0.042 \mathrm{~m}$ and $0.039 \mathrm{~m}$ for the means, the root-mean-square and standard deviation, respectively. Fig.2 illustrates the distribution of the GCPs, where the points around the landslide area to ensure the quality of the datasets.

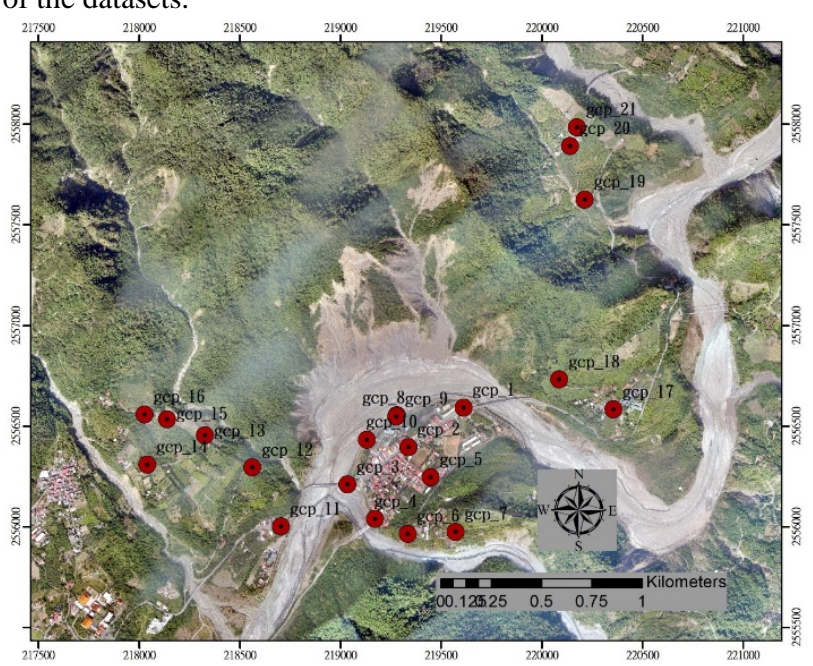

Figure 2. Distribution of ground control points

\subsection{Orthomosaic Image Comparison}

Based on the orthomosaic images, the evolution of the landslide is capable to estimate. Fig. 3 demonstrate the physical changes mostly by means of vegetation of the canopy. The date of image acquisition are indicate in up-left corner with in each images. Note that in the center region of each image, the landslide enlarged up-slope, meanwhile the patch of the canopy slid downslope. To calculate the horizontal displacement within the sliding area. Two methods have been used: 1. Visual identification artificially and positioning by $>30$ targets of distinct trees/canopies from each periods. Then calculate the displacement in each image pairs. The result shows the maximum horizontal displacement is higher than $69 \mathrm{~m}$. 2. By means of particle image velocimetey (PIV), the mean displacement within small windows size (Chang et al., 2005). The result shows near flanks of the sliding area still demonstrating signification displacement. Nevertheless, caused too large displacement, image correlation is fail to estimate total movement in center of the landslide, as revealed by artificial identification.

\subsection{DEM of Difference (DoD)}

More than 10 Digital surface models (DSMs) generate by means of UAS photogrammetry and UAS LiDAR. The topographic change can be simply subtract one from another, thus the geomorphologic difference (DoD) can be interpret as vertical morphological change. The topographic profile across the main body of landslide shows on upslope by subsidence, whereas the lower slope by slightly uplifting (Fig. 4). These behaviors demonstrate exactly the retrogressive sliding activity across the main body. Regarding to the total area, Fig. 5 illustrates the distribution of topographic change, whereas the maximum activate are occurred during the period of 2015 to July 2017. The landslide activity ceased since July 2017, however reactivated again from December 2018.

\subsection{UAV LiDAR}

The LiDAR sensor mounted on a UAV becomes a new powerful tool for geomatic technology. This study we integrate autonomous unmanned helicopter Pulse Aerospace Vapor 55, carrying Riegl VUX-1 UAV LiDAR with Trimble Applanix AP20 for the surveying mission. Based on the drone and instrument capacity, adjusted by the terrain landform, the optimal drone mission planning and scanning parameters are thus assigned, thus capable to acquire dense point clouds more than 150 points $/ \mathrm{m} 2$ in nadir direction for a single fly line. To access the dataset, several software packages are used, including: the Trimble Applanix POSPac Mobile Mapping Suite software, GNSS-Aided Inertial post-processing for georeferencing data collected from UAS LiDAR. Compared with the data point measured from site surveying by e-GNSS, RTK (real time kinematic GPS survey) and total station, ground control points and check points, the elevation errors is less than five centimeters. Two UAV LiDAR data set are acquired in July and December 2018, the results revels that at least $2.5 \mathrm{~m}$ of horizontal displace within sliding area, and the volume of erosion and deposition of at least of 0.4 and $0.52 \mathrm{Mm} 3$, respectively.
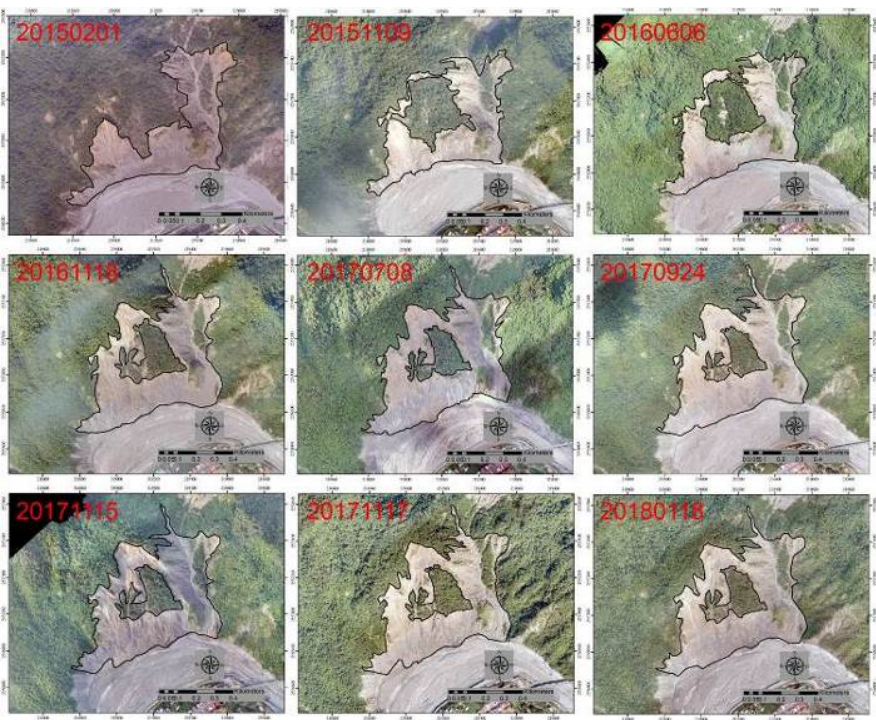

Figure 3. Orthomosaoic images acquired in different periods 


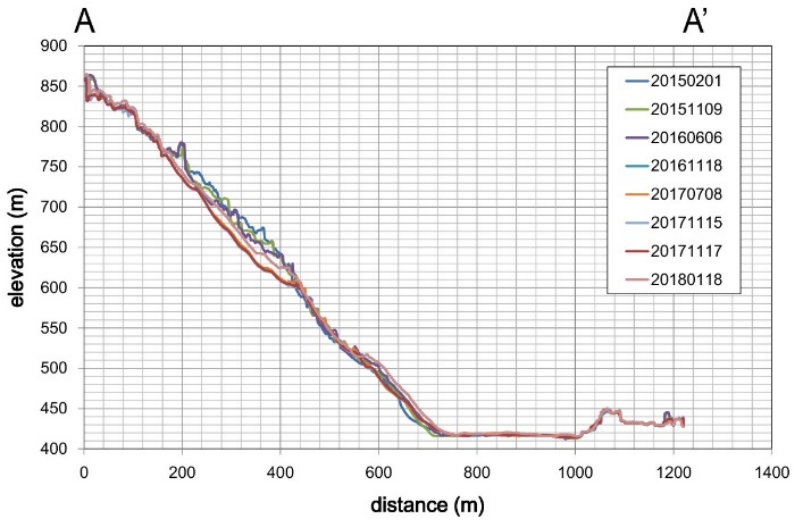

Figure 4. Geomorphologic profiles across landslide area
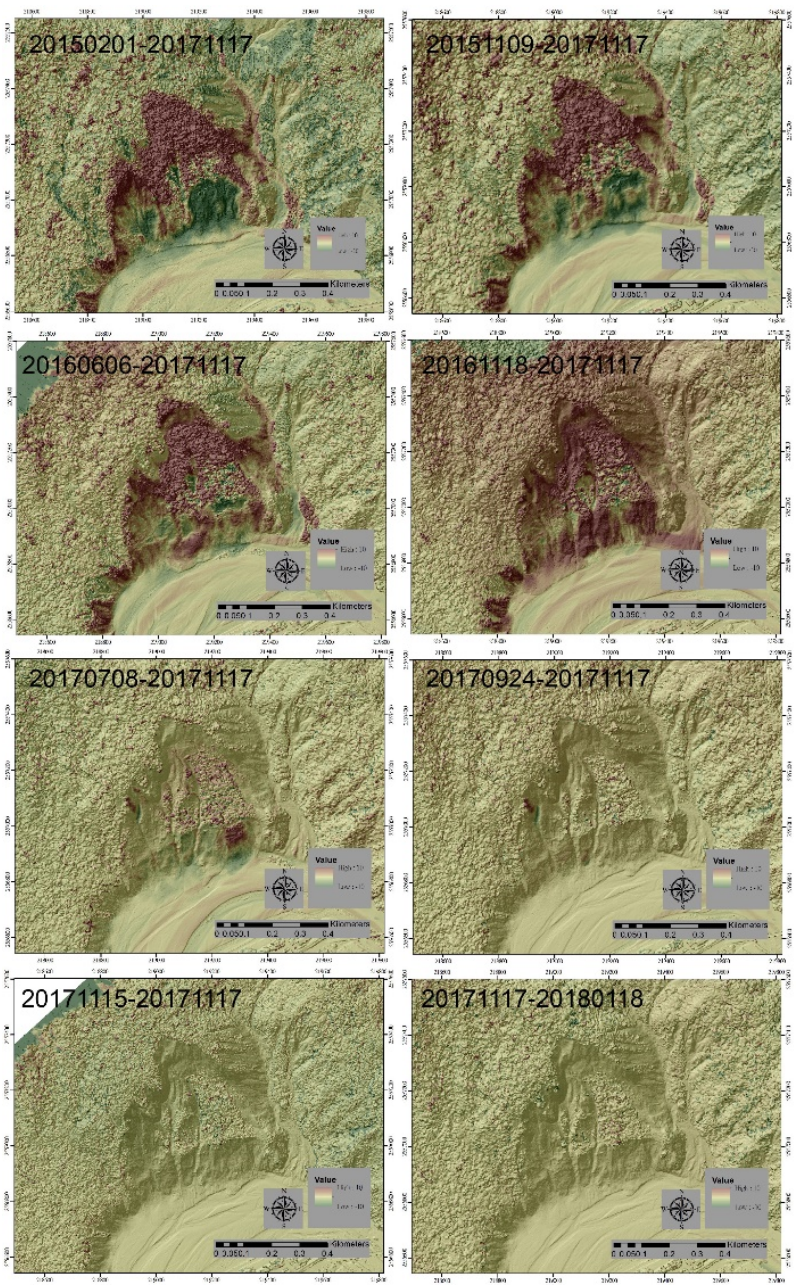

Figure 5. Topographic changes of the landslide area

\section{ACKNOWLEDGEMENTS}

This work has been partially supported by Ministry of Science and Technology, Taiwan (MOST 108-2119-M-027-001).

\section{REFERENCES}

Chen, R. F., Chan, Y. C., Angelier, J., Hu, J. C., Huang, C., Chang, K. J., and Shih, T. Y., 2005. Large earthquake-triggered landslides and mountain belt erosion: the Tsaoling case, Taiwan”, Comptes Rendus Geoscience, 337, 1164-1172.

Chang K.J., Taboada, A. and Chan, Y.C., 2005. Geological and morphological study of the Jiufengershan landslide triggered by the Chi-Chi Taiwan earthquake" Geomorphology, 71, 293-309. Chang K.J., A. Taboada, A., Chan, Y.C. and Dominguez, S., 2006. Post-seismic surface processes in the Jiufengershan landslide area, 1999 Chi-Chi earthquake epicentral zone, Taiwan. Engineering Geology, 86, 102-117.

Chan, Y. C., Chen, Y. G., Shih, T. Y. and Huang, C., 2007. Characterizing the Hsincheng active fault in northern Taiwan using airborne LiDAR data: detailed geomorphic features and their structural implications. Journal of Asian Earth Sciences, 31, 303-316. doi: 10.1016/j.jseaes.2006.07.029.

Chang K.J., Chan, Y.C., Chen R.F. and Hsieh, Y.C., 2010. Evaluation of tectonic activities using LiDAR topographic data: an example from the Nankan lineament, northern Taiwan. Terrestrial, atmospheric and oceanic sciences, 21, 463-476.

Deffontaines B, Chang K.J., Champenois J., Fruneau B., Pathier E., Hu J-C, Lu S-T., Liu Y.C., 2017. Active interseismic shallow deformation of the Pingting terraces (Longitudinal Valley-Eastern Taiwan) from UAV high-resolution topographic data combined with InSAR time series: Geomatics, Natural Hazards and Risk, 8,1, 120-136.

Deffontaines B, Chang K.J., Champenois J., Lin K.C., Lee C.T., Chen R.F., Hu J-C, Magalhaes S., 2018. Active tectonics of the onshore Hengchun Fault using UAS DTM combined with ALOS PS-InSAR time series (Southern Taiwan). Nat. Hazards Earth Syst. Sci. (NHESS), 18, 829 - 845.

Deffontaines B, Chang K.J., Lee, C.T., Magalhaes S., Serries, G., 2019. Neotectonics of the southern Hengchun Peninsula (Taiwan): Inputs from high resolution UAS Digital Terrain Model, updated geological mapping and PSInSAR techniques. Tectonophysics. 767, 128-147, inpress.

Hsieh, Y. C., Chan, Y. C., Hu, J. C., Chen, Y. Z., Chen, R. F. and Chen, M.M, 2016. Direct Measurements of Bedrock Incision Rates on the Surface of a Large Dip-slope Landslide by Multi-Period Airborne Laser Scanning DEMs. Remote Sens., 8(11), 1-22, https://doi.org/10.3390/rs8110900.

Chang K.J., Chan, Y.C., Chen R.F. and Hsieh, Y.C., 2018. Geomorphological evolution of landslides near an active normal fault in northern Taiwan, as revealed by lidar and unmanned aircraft system data. Nat. Hazards Earth Syst. Sci., 18, 709-727, https://doi.org/10.5194/nhess-18-709-2018.

Hung, C.-L.J., James, L.A., Hodgson, M.E., 2018. An automated algorithm for mapping building impervious areas from airborne LiDAR point-cloud data for flood hydrology. GIScience \& Remote Sensing 55(6), 793-816. 